\title{
What the Community Learns: International Service-Learning in Yucatán, México
}

Claudia Chapas-Cortés

Universidad Marista de Mérida

\section{Recommended Citation:}




\title{
What the Community Learns: International Service-Learning in Yucatán, México
}

\author{
Claudia Chapa-Cortés \\ Universidad Marista de Mérida
}

\begin{abstract}
Colleges and universities have increasingly adopted international service-learning (ISL) as a pedagogy for students studying abroad. The literature on these programs has illustrated that international students receive more attention than host communities as objects of study. Host groups often face real challenges caused primarily by historical and social factors that contribute to their longterm marginalization. If ISL implies mutual learning and reciprocity between host communities and students, it is important to question how communities live the ISL experience - in other words, what do they learn? This study introduces the voices of a group of women in Mérida, Mexico, who participated in an ISL program. Utilizing an ethnographic approach, including participant observation, focus groups, and interviews, the study discussed in this article produced findings that suggest that communities participating in ISL gain important learning outcomes in areas such as empowerment, skills, values, and collective organization.
\end{abstract}

Keywords: community, international service-learning, mutual learning, reciprocity

This article provides a preliminary analysis of how a local host community in Mérida, México, experienced and learned from international service-learning (ISL). The goal of this research was to elevate the importance of scholarship that critically analyzes the experiences of ISL host communities in order to contribute to a broader discourse on the benefits of ISL. Such a goal is especially important given the potential of ISL to perpetuate colonial perspectives and practices. In addition to the ethical and political relevance of conducting research on ISL host communities, one of the primary reasons to engage in such scholarship is to better understand the role these communities play in the educational process. In accordance with Freire (1976), such communities make up potential educational communities that act as educators and learners at the same time, a dynamic that has not been well studied and that is possibly generating lessons that can contribute to positive societal change. If the growth of ISL reflects increased globalization of education, then it is important to understand how learning flows in both directions - between student visitors and host community members (Hammersley, 2012).

There is considerable literature on the changes that globalization has brought to communities, education, and the dynamics that have been generated around it (Stromquist, 2008). One of the major trends resulting from increased global integration is the internationalization of higher education, including international student mobility. As part of this mobility, there has been growth in the institutionalization of ISL as pedagogy. International service learning, which incorporates service into study-abroad curriculum, has the goal of gaining "deeper understanding of global and intercultural issues, a broader appreciation of the host country and an enhanced sense of their own responsibilities as citizens, locally and globally" (Bringle, Hatcher \& Jones, 2011).

The literature on ISL has highlighted both positive and negative outcomes associated with combining study-abroad curriculum with service. Studies have illustrated, for example, how students gain a sense of commitment to community engagement (Tonkin \& Quiroga, 2004), global citizenship (Hautzinger, 2008), and empathy (Stratman, 2013), among other findings. These studies suggest that such international academic experiences can generate an important transformation in students (Allen, Boots, Bugas, Parsons \& Swap, 2014; Whitaker \& Bathum, 2014). Others, such as Kahn (2011), have 
shown the challenges of ISL, "particularly those introduced by the cultural complexities and inequalities that foreground many ISL practices and supporting ideologies" impacting all partners (p. 113). There is also a general concern among some researchers about the ethical dilemmas and consequences of such experiences for host communities (Crabtree, 2013).

In general, the literature on ISL experiences has focused primarily on the transformations of student participants (Cox, Murray \& Plante, 2014; Lovett \& Nain, 2015; Larson \& Fay, 2016; Pless, Maak \& Stahl, 2011). Little attention has been given to communities that receive these students (Braskamp, Braskamp \& Merrill, 2009). Despite the key function of the communities within ISL partnerships, their experiences and what they have learned have had little weight in the ISL literature. Their role is typically relegated to that of a recipient of the program and not as an educational agent, as learners who not only receive benefits but also provide dialogue and education (Freire, 1976).

In some studies, communities have been valued not as educators but as a necessary part of an international experience (Martínez-Odria, 2008; Miron \& Moely, 2006; Whitaker \& Bathum, 2014). A key focus of the current study was on the importance of identifying and recognizing the consequences, transformations, and/or learnings of the host community in ISL programs (Crabtree, 2013).

\section{About the Community}

This article reports on the first stage of a broader research project seeking to analyze the learning experiences of an ISL host, a community of women within an economically distressed neighborhood of Mérida, Mexico. Mérida is located in the south of Mexico in the Yucatán Peninsula, a region with a strong indigenous and rural heritage. The dominant Mayan population in the region lends Mérida a cultural and historical context like no other in Mexico (Gaultier, 2003).

During the 1980s and 1990s, changes within the Mexican economy and politics, including passage of the North American Free Trade Agreement (NAFTA), had clear consequences for the livelihoods and wellbeing of Mexican families. Once such consequence was an increase in the number of migrants, including those going to the United States (Hartman, 2011). In the Yucatán, economic and political policies during the final decades of the 20th century brought unemployment and poverty in the countryside and massive rural-urban migration (Lizama \& Bracamonte, 2014). Families from across the Yucatán and from other states in Mexico arrived in Mérida seeking income opportunities, resulting in significant geographical, economic, and political changes in the city. In particular, there was a high demand for new housing for migrant families, leading to the formation of informal settlements on the periphery of the city. These settlements slowly developed into housing programs that would help mitigate the massive demographic shift toward the city. In 2001, there were 3,800 inhabitants in these neighborhoods; by 2006, that population had tripled (Caballero, 2013). One of the consequences of the city's expansion was a lack of basic services and schools. The southern part of Mérida grew during the previous two decades by almost 10,000 hectares to host thousands of immigrant families coming from Mayan communities inside the Yucatán and from other states in Mexico (Caballero, 2013). The women who participated in this study reside in two of these new neighborhoods that developed from this migratory dynamic. The women's livelihoods vary, but they tend to work in the service sector; some clean houses for a living, others sell items in regional markets, and others are housewives.

The women in the study created a non-governmental organization (NGO) under Mexican law. The NGO's mission is to contribute to the social, cultural, and economic development of the southern zone of the city through projects and activities that improve the quality of life for themselves, their families, and their community. The site was chosen for this study because of the long-term commitment to the ISL project and the mutual interest of both the university and neighborhood association in continuing the partnership. For the purposes of this study, it is important to note that the NGO is referred to synonymously as the community. 
The ISL partnership began unofficially in 2003 through the efforts of a U.S. private higher education institution searching for an ISL site for its students. Through the coordination of a local university professor, meetings were held between members of the community and the U.S. university to find out whether there was interest in the program. This professor was key to forming the partnership because he was involved with the host community and knew the participants fairly well through social and academic projects that ultimately led to the first encounters between community members and the U.S. university. The partnership started officially in 2005 when an informal network of women in the Mérida neighborhood planned service opportunities for university students. The university financially sponsored the program and made an annual commitment to send students to work in the community. From the beginning, decisions related to the program - namely concerning student activities, projects, fundraising, and field trips - were made by the women leading the NGO in the community. In turn, the university partner determined how many students would participate, the dates of the program annually, and the number of service hours spent in the community.

One of the primary projects developed by the NGO is known as Casas Digitales, or Digital Houses (DH). The initiative began in 2013 with the goal of integrating learning communities into the homes of neighborhood volunteer families. The participating families donated space on their property to build computer laboratories offering free access to computers connected to the Internet along with afterschool programs for children. Since its inception, the DH project has been the core of the ISL program, which engages study-abroad students with youth from the community one day per week for 10 weeks throughout the year. More recently, the program has operated five DH sites for children of ages 4 to 16 . Women in the community, supported by a local teacher, developed an activity plan with specific objectives, including promoting a sense of community, identifying and addressing school problems, using technology and online social media, enhancing knowledge of local and foreign culture, and fostering respect and tolerance toward different members of the DH. For at least the past 10 years, the women who make up the NGO have collaborated with the ISL program to achieve these goals.

Each year, the number of university students who participate in the ISL program varies but typically ranges between eight and 12 students. The students come from diverse backgrounds, and their ages are typically between 19 and 22. Their majors are also diverse and tend to be related to social sciences and humanities, including anthropology, sociology, peace studies, and Latin American studies. Though an advanced level of Spanish is not required for the program, most students have at least intermediate proficiency; in recent years, numerous Latinx students have participated with even stronger Spanish language skills.

The ISL program structure is based on weekly three-hour sessions facilitated by university students with youth in the community. During the 10-week period, students are usually assigned across five digital houses. The women in the community who participate in the program, and who took part in this study, are 30 to 60 years old. They share an interest in providing a better life for their children, and the $\mathrm{DH}$ project represents one effort to achieve that goal. At least $70 \%$ of these same women are founders of the group, which began approximately 15 years prior to this study, while the rest joined later. Initially, projects such as DH developed from informal processes led by women gathering to discuss ways to engage youth, and in recent years such processes have become more formalized as part of an official NGO. The women's motivations for participating in the organization vary, but the two most important are the priority they place on their children and community, and their preference to work as a group. Not surprisingly, most who participated in this study had collaborated in prior projects that benefited their community. María, for example, had been involved in the community for 15 years; she had been neighborhood president on two occasions and had facilitated significant changes in the community such as the construction of a school and development of a nursery and urban gardens. At the same time, she described her living conditions as a constant struggle without basic infrastructure such as electricity and water.

During the early years of the NGO's development, activities took place in homes, which were the only available meeting space. Despite their challenging living conditions, as described by María, the 
women committed their time and their homes to plan and implement community development projects. For example, as Gabriela shared, "I didn't even have anywhere to sit; we rolled like garbage carried by the wind." Martha noted, "I like to help, to collaborate. ... We do not sit down to wait but to do something for our children in our homes." In other words, the women voluntarily found ways to support programs that benefited their children and the community.

In general, as the women in this study expressed, it was important working as a community to identify objectives, and fulfilling those objectives made them feel proud to belong to the group. The strength of the women's ability to work as a community and build programming in support of youth provided an excellent foundation for an ISL partnership.

\section{Scholarship on ISL Host Communities}

ISL is a pedagogy that, when done well, offers opportunities to increase knowledge about social equity (Mitchell, 2008). Cornejo (2012) questioned the current educational system in Latin America and argued, in line with Cobo (2005), that education should be humanized, promoting values that favor human rights, justice, equity, and social development - a model that contrasts with values like individualism and competition that are encouraged by globalization, the promotion of private interests, and expansion of the global market (Stromquist, 2002). A more humanized approach to education requires strategies that foster a more just and equitable world, and that prioritize reciprocity through what Hartman, Paris, and Blache-Cohen (2014) referred to as "fair trade learning." The growing literature on ISL as a teaching strategy has suggested that, if developed properly, ISL may comprise one such humanizing strategy in higher education, promoting values that focus on the human experience (Cornejo, 2012) that ultimately will foreground fair-trade learning principles such as economic equity, equal partnership, mutual learning, cooperative and positive social change, transparency, and sustainability (Hartman, Paris, \& Blache-Cohen, 2014).

Unfortunately, the voices of local communities have largely been silenced in the scholarship of these international academic initiatives, which highlights the often-marginalized circumstances of host communities. As Cortés (2007) explained, the model of neoliberal economic development has preserved traditional power structures and the interests of privileged minorities, and has reproduced and kept excluded entire populations from economic, social, and political participation. This includes how host communities contribute to and learn from ISL programs. A frequent criticism is that, although international students who work in marginalized communities benefit from their experience, the host communities have the potential to be used as objects for purely academic purposes (Sharp, 2015), not receiving substantial benefits or learning when it should be mutual. Given that ISL communities are undoubtedly educational agents, their contribution to intercultural experiences is invaluable, not only educationally but also socially. A more humanizing education that rescues values of justice, equity, and social development, as Cobo (2005) pointed out, could be further emphasized through ISL strategies and goals.

One of the strengths of ISL is the possibility of generating mutual learning based on a cultural exchange within a context of social inequality. To explore this type of mutual learning, this study drew on the concept of transculturalism, defined decades ago by Ortiz (1940) as the way in which a person deals with their own culture and others by establishing an interaction and dialogue that results in an enriched cultural tradition and practice. This approach promotes an understanding of intercultural behavior that is dialogical - one, for instance, that considers the daily coexistence of international students and local community members and the mutually enriching cultural practices and values of each group. In contrast to a unidirectional view of student learning and benefits common to most ISL research, a transcultural perspective explores the potential to enrich all individuals from different cultural perspectives, different forms of knowledge, communication, and behavior in general (Milhouse, Asante, \& Nwosu, 2001). Transculturalism was employed in this study as a way to interpret the relationships between the different groups and explore what they respectively brought to a mutually beneficial (reciprocal) learning process. 


\section{Methods}

The qualitative research tradition emphasizes recognizing the complexity of reality for humans (Denzin \& Lincoln, 2011). This study sought to explore the complexity of the experiences of the women participants over many years of hosting the ISL program in Mérida. It explored how they understand the program within the context of their lived experiences of adversity, marginalization, and discrimination. In doing so, the study sought to answer the question of how host communities experience ISL programs.

The study used an ethnographic approach, including observing what happened during the ISL program as well as investigating what the hosts thought about the program - what it had meant to them - through collecting and analyzing narratives. The latter also meant understanding the women's life frames (Geertz, 2005) and focusing on not only what was on the surface but also what was behind it. The study therefore centered more on the deeper meanings behind human behavior than on quantifying that behavior. The goal was to understand what the women experienced in an ISL program, and the research methods selected allowed for gaining a deeper understanding of the meaning they gave to that experience.

Data collection was conducted in Spanish, and methods included participant observation, focus groups, and in-depth interviews (from January 2017 to March 2018) in two stages. The first stage of research consisted of 40 hours of participant observation conducted (from January to March 2017) during the 10-week ISL program in all the digital houses in the weekly sessions with neighborhood youth. Observations were conducted each week at the different digital houses in the afternoon for approximately four hours while the program was carried out by university students and community members. Additionally, two 45-minute preliminary one-on-one interviews took place, one with the former general coordinator of the project and a second with the supervisor of a federal grant received by the NGO. These interviews were held in the community at one of the digital houses where the program was taking place. Both interviewees were chosen because of their key participation in the NGO and the ISL program. Following this first 10-week ISL program, a focus group with nine women was conducted to gain a better understanding of their experiences participating in the program. Participants were selected because of their availability, willingness, and active participation. The focus group session was approximately 70 to 80 minutes long and took place at a community center, which was suggested by the participants and was close to the digital houses where most of the women gathered when they had important meetings as a group.

The second stage of research (conducted in January 2018) included an additional 40 hours of participant observation with a new group of U.S. students during a second 10-week period (from January to March) and the first stage of interviews with the five DH supervisors. The interviewees were selected because of the role they played in the project as leaders; they were the ones who carried out the ISL program on a practical basis and interacted with U.S. students, local children, and their mothers. These leaders decided what topics needed to be covered during the program and ultimately lived the experience of participating in ISL directly. The interviews took place at each of the five digital houses - that is, at each supervisor's home, typically sitting in the living room or patio of the house.

The instrument used for the in-depth interviews was a guide developed out of the previous participant observations and based the research question. The goal was to inquire about the community members' motivation to participate in the program and also what they thought and felt about the ISL program and the U.S. students working in their community. Each interview lasted 45 to 60 minutes. The results of the initial data collection provided a foundation for developing a guide for continued longitudinal research involving a second series of in-depth interviews and focus groups. All methods employed focused on the experiences and perceptions of the women who hosted the ISL program. 
6 | International Journal of Research on Service-Learning and Community Engagement

Most of the interviewees have been involved with the DH project for at least eight years. For others, including two of the coordinators of DH, this was the first time they were engaged with ISL students.

In sum, a total of 13 interviews were analyzed. Table 1 lists the demographics of the research participants (for privacy and confidentiality, all names are pseudonyms). All interviews, focus groups, and field notes were transcribed and coded manually. The software program Quirkos was used to assist in the coding and to create themes and sub-themes.

Table 1. Group Demographics

\begin{tabular}{|c|c|c|c|c|c|}
\hline$\#$ & Name & Age & Highest Educational Level & Place of Birth & Role in the NGO \\
\hline 1 & Amalia & 30 & Bachelor's & Mérida, Yucatán & $\begin{array}{l}\text { Former NGO } \\
\text { Coordinator }\end{array}$ \\
\hline 2 & Blanca & 30 & $\begin{array}{l}\text { Currently completing bachelor's } \\
\text { in law }\end{array}$ & $\begin{array}{l}\text { Zamora Zapata, } \\
\text { Quintana Roo }\end{array}$ & DH Supervisor \\
\hline 3 & Carmen & 42 & Elementary school & $\begin{array}{l}\text { Libre Unión, } \\
\text { Yucatán }\end{array}$ & Participant \\
\hline 4 & Cecilia & 38 & Middle school & Mérida, Yucatán & Participant \\
\hline 5 & Elisa & 46 & Middle school & Abalá, Yucatán & Participant \\
\hline 6 & Elizabeth & 58 & Middle school & $\begin{array}{l}\text { Citibcanchen, } \\
\text { Yucatán }\end{array}$ & $\begin{array}{c}\text { Former President of } \\
\text { NGO }\end{array}$ \\
\hline 7 & Elvira & 38 & High school & $\begin{array}{l}\text { Citibcanchen, } \\
\text { Yucatán }\end{array}$ & Participant \\
\hline 8 & Gabriela & 49 & Middle school & Naranjo, Campeche & DH Supervisor \\
\hline 9 & María & 58 & High school & $\begin{array}{l}\text { Guanajuato, } \\
\text { Guanajuato }\end{array}$ & $\begin{array}{l}\text { DH Supervisor \& } \\
\text { President of NGO }\end{array}$ \\
\hline 10 & Martha & 34 & Associate degree & Mérida, Yucatán & DH Supervisor \\
\hline 11 & Mónica & 42 & Elementary school & $\begin{array}{l}\text { Libre Unión, } \\
\text { Yucatán }\end{array}$ & Participant \\
\hline 12 & Patricia & 33 & Middle school & Mérida, Yucatán & DH Supervisor \\
\hline 13 & Zazil & 40 & Bachelor's & Mérida, Yucatán & $\begin{array}{l}\text { Federal Grant } \\
\text { Coordinator }\end{array}$ \\
\hline
\end{tabular}

\section{Findings}

In general, participants' responses were positive with respect to the ISL program experience. Women gave optimistic impressions of U.S. students and recognized that they learned as a result of the students' presence in their community. All of the women agreed that different ways of thinking encouraged through the program were an enriching part of the ISL experience. They also expressed 
challenges, but these were specific isolated cases and did not constitute a broad criticism of hosting U.S. ISL students. In fact, all participants stated enthusiastically that each year they awaited the arrival of the next new group of students. Table 2 illustrates interviewees' responses organized into one main theme: Learnings or transformations resulting from the ISL experience.

Table 2. Interviewees' Responses

\begin{tabular}{lll}
\hline \multicolumn{1}{c}{ Theme } & \multicolumn{1}{c}{ Sub-themes } \\
\hline & $\bullet$ Relationship with the organization and children \\
Learnings or & $\bullet$ Self-consciousness and empowerment \\
transformations & $\bullet$ Skills and values: patience, respect, culture, language, and \\
& & friendship \\
& $\bullet$ & Political issues, stereotypes and identity \\
\hline
\end{tabular}

\section{Learnings or Transformations}

What occurred during the daily experience of working with the ISL program appeared in the data as lessons learned or transformations experienced by the women. That is, the women's comments reflected what they learned and/or how they experienced transformations from the ISL experience throughout their years hosting the program. All of the women interviewed mentioned several lessons learned throughout the time they participated with the ISL students identified in Table 2. The remainder of this section outlines these lessons.

Relationship with the organization and children. One learning outcome from the development of the NGO and the related partnership with the ISL program was the way the women understood the role of the organization. The strong sense of collaboration between the women participating in the program and among the DH coordinators was reflected in comments about their closeness and strength as a group and their capacity to undertake initiatives by themselves without assistance from others. As Maria noted, "We were only used to asking ... It is hard for us to start by ourselves; unity is strength." Others highlighted coordination and organization among the group as well as the ability to pursue change in the neighborhood to improve lives. Participant observation affirmed that the relationships generated between the women united the group. Another participant, Patricia, explained that she felt they were like a big family fighting for the same cause.

The wellbeing of children appears to be the primary cause taken on by the women. The DH and ISL programs were seen as helping the women build relationships with neighborhood youth. Gabriela, who was married and did not have any children, stated that she thought she had learned how to interact with youth after she started supervising one of the digital houses: "I do not know how to say it, but I understand children better; they are children, they act like children; I have more patience, I understand them better. ... I am not as impatient as I used to be." A lesson to be interpreted here is that the DH project and ISL program offered a context for adults to interact differently with youth in a positive environment that incorporated both learning and fun for the adults, the international students, and the children.

Self-consciousness and empowerment. The women became more self-aware as a result of the DH project and ISL program. In this regard, some of their responses directly reflected an increase in self-consciousness. They spoke about appreciating who they were, their identities, and what they had to offer to the community. They also spoke about creating an example for their children to witness the effort they had invested in the community, with the hope that when they became adults, they would replicate the investment in their communities. "We can do things; it will be more useful for us, and it's an example for our children," claimed Martha. 
Another interviewee mentioned that she had learned the idea of empowerment from the ISL program and through interaction with the international students during workshops. The topic emerged through conversation, though not all the women interviewed knew the meaning of the term empowerment. One participant explained that "it could be losing the fear of speaking; many times we are shy and we do not even want to talk. ... The thing is that someone starts to speak and we let go." Maria, a DH coordinator, stated during the focus group that empowerment, to her, was "knowing that I am something special, that I can, that I know where I'm going and what I want I will get and that if I can, also my partners can, learning to live together as a group."

One outcome of the focus group was that the women learned from one other about empowerment since many were not familiar with the term. When María mentioned her definition, however, many nodded as if in agreement. Such learning experiences were common among the women when they met in groups. Interestingly, the need to be organized for hosting the ISL program generated informal learning that resulted in the development of a collective consciousness about women's power. That is, lessons learned as a result of ISL programs may not have been always exclusively experienced through coexistence with the students. In this case, learning took place as an outcome of the interaction among the women as a result of planning ISL. In this regard, ISL can be understood as a key component of the women's collective learning process.

Skills and values: Patience, respect, culture, language, and friendship. The women who made up the ISL host community in this study learned from one another and also from their engagement with ISL students. In the interviews, the most important outcome of this engagement indicated was the relationship nurtured between children from the community and international students. They all agreed that the program produced important social bonds between students, children, and women that in many cases continued beyond the program. These bonds have been especially sustained in recent years with the invention of social media. To the women, the programmatic and post-program interactions between the students and neighborhood children not only improved academic and social skills among the youth but also nurtured values, such as respect, that are intangible but highly valued by the women. As Martha noted:

It benefits the children a lot; the moms too. Apart from what they learn, I think they keep the feeling and that friendship and that love they give them, because they come so selflessly ... the love they give to the children. We know for sure, because there are students who left, and last year we were visited by two who were with us two years ago; we even have contact with them by Face[book], and they always refer to us as my family. I tell you, the link formed between us is very beautiful; it is not only with the children, it is part of us, the family.

Not only did the children remain in contact, but the women also continued to communicate with many of the students. As Gabriela reflected, "I think I have learned because they tell you about the customs and what they do there ... like the teacher Julieta; I read her letter as if she had sent it to me yesterday."

Blanca mentioned that she learned many things from the presence of ISL students. She spoke specifically about having more diverse friends and the value of understanding another culture and language. "They leave many learnings for children; the enthusiasm of the guys and girls is something that is contagious," said María. Although all students were different and had different personalities, respondents agreed that they were good people, had great attitudes, and in most cases left invaluable knowledge in the community. As Blanca said, "They are not closed. They have an attitude of teaching, of sharing. They could be doing this at home, but they decided to come." Although the students spend only 10 weeks in the community, a sense of affection develops for the students as a result of their weekly engagement with the women and children. Moreover, the consistency and return of students every year for more than a decade has left a feeling of satisfaction among the women.

Martha noted how students' attitudes taught her a lesson about simplicity. As she explained, students "are not pretentious ... are very spontaneous, are not afraid, do not say no, do everything, always want to help." Gabriela said she valued the students' level of commitment 
because they did not have children in their countries of origin and were mostly single. ISL students also had a significant influence on her own behavior: "They take their role seriously; they are looking out for us. If they do it, why wouldn't I? ... I was not very affectionate. I care now; they are affectionate." Similar motivations were mentioned by another interviewee, Zazil, who commented that the presence of these students gave hope and motivated learning at the community level:

Meeting young people who participate in social projects as volunteers, from any latitude, makes me believe that we can all be better people and help build or perhaps rebuild the world in which we live. The young volunteer not only gives time; they also give encouragement, hope, confidence, certainty and impulse to be better, to contribute to a community feeling better about itself. By being present in the community, individual and collective identity is strengthened.

Mutual learning also takes place through intercultural exchange related to language, food, and music. The numerous informal conversations that emerge through contact between students and community members gives both parties a lens on the other's way of life. Even when communication between volunteers and coordinators is not ideal due to language barriers, after 10 weeks of being together, they find that language challenges fade into the background as mutual sharing of skills became more important, including how to be flexible.

Political issues, stereotypes, and identity. The topic of politics regularly emerged in conversations, not just for the women involved in the program but also for participating children. María emphasized that, following the 2016 U.S. presidential election, mothers and children were interested in understanding political issues related to the new president. The ISL students generally showed sensitivity toward the local community about U.S. political issues. Reflecting on the impact of the presidential election, during which Mexico (including NAFTA) and immigrants from Mexico became a central theme, María talked about a time when she heard one of the students talking to the children: "In one of the classes with Bruno, I heard he was apologizing to the children, he was saying, 'I'm sorry, I'm really sorry, I did not vote for him [i.e., Trump]; excuse me'.... And the children understand; we know nobody was to blame for such a bad choice."

Interestingly, the women were more concerned with whether the election would impact the ISL program. For example, Gabriela thought that students would no longer want to come to Mexico: "We have never told them not to come. On the contrary, we want to see them, we want them to come; we have not said at any time they shouldn't come." Such interest in crossing boundaries, whether political or otherwise, and engaging with difference was central to the women's motivation to participate in the ISL program. This motivation included the importance to them of connecting with different people, in terms of not only age and academic training but also life histories and diverse cultural backgrounds. They saw these interactions as important for breaking stereotypes through students discussing important topics with the community. One outcome of such discussions was reconsideration of the ways the host community members thought about diversity in the United States. As Martha explained,

This time with [ISL students] Emilia and Joan, children ask them what does it mean to be Latin American? ... And then Emilia explained to them, "Well, my parents are from Guatemala; they moved to the United States, I was born there," so they learn that the parents do not necessarily have to be from the U.S. for children to be from the U.S., but rather it is a combination [of people] that is taking place and from there they start talking about it and they begin to ask, "How do they talk there in Guatemala? If they are from there then they do not speak English. ... You are not from the U.S. because you do not look like someone from the U.S.; someone from the U.S. has to be blond and tall."

Such stories about the impact of U.S. university students on children were common among the women. They expressed how they, along with the children, personally learned about challenging stereotypes. As Amalia noted, "I think that the simple fact of living with people from another country 
does a lot of good, because [the children] come out of their routine; they get to know new things, how a normal day is ... also they go out of their comfort zone." Moving out of their comfort zone with the ISL students, as the women explained, helped children develop creativity, new interests, and imagination. As Martha noted, "They do change, because only by meeting people from another culture they learn - a little language, interest, imagination, curiosity, what is the United States ... Where do they want to go? Chicago! Do they eat cochinita?"

Finally, Brenda, one of the DH supervisors, mentioned that through her interaction with a U.S. student, she realized that there were not as many differences as she previously believed. "We talked about poverty. The living conditions here I thought were very different from those in the U.S. Joaquin taught me they are not so different; there are divided zones, poor neighborhoods too. We are more similar than different." Such sentiments highlight learning outcomes that resulted from the women's long-term engagement with ISL students. Overcoming communication barriers - "understanding we are more similar than different"-was a collective lesson learned by all. The fact that the interviewees identified ISL students as good people possessing positive and easy attitudes could contribute to the construction of a more equitable relationship across cultures. Such small forms of intercultural relationship building do not eliminate the obvious power differences inherent in the relationships with U.S. students, who have the privilege of visiting an economically distressed neighborhood in Mexico. Generally, both the hosts and the students are aware of this privilege but do not let it hinder efforts to build relationships that may foster coexistence and combat prejudice and racism.

\section{Discussion}

The voices illuminated in this study are valuable because they begin to explain how host communities experience ISL programs. They show that not only are students transformed by ISL experiences, but host communities also learn from and contemplate intellectually their experiences engaging with university students. The fact that the community members feel they participate in a process as equals with a group of foreign students from the United States is very important since it reflects the strength of a successful long-term ISL partnership. The role of the community in the teaching-learning process is clearly indispensable (Freire, 1976); however, the community's contributions and learning process are rarely researched, analyzed, or published.

There were subtle yet important issues raised in the responses of the women who participated in this project. Their attitudes were always positive, cheerful, and welcoming; they received the students with an open sense of collaboration, patience, and understanding. They were willing to overcome language or organizational obstacles. In addition, notwithstanding U.S.-Mexico political tensions during the time of this research, especially in relation to immigration, all of the women were extremely grateful for the presence of ISL students from the United States. The fact that the students worked with the children without receiving remuneration and that none of the students themselves had children made the women appreciate the experience even more.

Continuity of the ISL program over many years has led to an openness among the women toward international students. The NGO's support of the ISL students developed over many years. Through subtle and often unseen processes for students, the dynamics of the community have changed in ways that are linked to the annual cultural exchange through ISL. The women in this study indicated that cultural exchange and friendship constituted the most important rationale for continuing the partnership. Initially, community development and project evaluation processes were new to the women, but they have begun to develop more structured program administration, teamwork-building mechanisms, and respect for each other's time. Indeed, through collaboration with the ISL program, the women began critically questioning the function of the NGO. They were pushed to define goals and objectives collectively and to identify challenges and how to address them. In transcultural terms, this community/organizational development process could be an indicator of elements that have been adapted from other types of organization, enriching one's own culture, and creating an alternative, enriched culture (Ortiz, 1940). 
The community of women who participated in this study highly value contact with others and the unity they have as a group. Despite their adversities and economic conditions, they remain committed to staying united, communicating and addressing their internal challenges as a group. These are values they consider indispensable. Children notice these values, and some mothers mentioned that the bond children develop among themselves and others could go beyond geographical and social borders. The support given by the NGO and the relationships established by the coordinators of the $\mathrm{DH}$ are important community assets. While there are clear infrastructure deficiencies in the neighborhood, and many social and economic challenges, the women demonstrate how solidarity among themselves and with others exemplifies social and cultural resilience and community-building strategies that can be learned. Cobo (2005) discussed a humanizing education in which values such as solidarity are highly encouraged, as are inclusivity and respect for other people. For the women, the ISL program encourages these values.

Of all the topics discussed by the women, U.S. politics stood out as the most divisive, especially given that this study took place within a year and a half following the contentious 2016 U.S. presidential election. Nevertheless, the women wanted their children to learn about the elections in the United States. They felt that talking indirectly about racism and immigration policies could result in children and women developing empathy and solidarity skills rather than reemphasizing racial and cultural differences. Furthermore, the diversity of the U.S. students was important. For the women and children, knowing people who do not fit the stereotype of a tall, White, blond American represents a learning experience about multiculturalism in the United States. Equally important is the lesson that every individual possesses unique characteristics. Contact with international students is therefore part of breaking the stereotypes children learn from previous experience or through the media.

The concept of empowerment mentioned and in some cases learned by the women is just one example of how intellectual topics are being discussed in relation to the ISL program. Women are reimagining their roles and questioning what kind of power they exert over themselves, their group, and the broader community. Such lessons could reveal a dynamic of mutual learning among both ISL students and the women that goes far beyond basic cultural exchange.

A deeper understanding of the mutual learning through ISL programs illuminates the dynamics of unearned privilege, which is often not examined in depth when analyzing the relationship between universities and the economically distressed communities that such programs traditionally seek to "serve." Openly discussing the dynamics of power and privilege between "those who serve" and "those served" establishes a relationship of fair-trade learning (Hartman et al., 2014), honesty, reciprocity, and mutuality between both groups (Baker- Boosamra, 2006). Through the lens of unearned privilege and reciprocity, researchers must question the extent to which ISL programs serve to further colonialism, whether intentionally or unintentionally (Sharp, 2015). None of the community members interviewed in this study mentioned any element that would lead to the assumption that forms of colonial extraction of knowledge were carried out over the many years of the program. The community itself developed the projects in which the students participated. The students had the flexibility to modify activities, and yet the objectives remained the same as those developed by the women.

Nonetheless, the inertia of privilege and power between North and South, while not necessarily tangible, remains ever-present in interactions of this type. In other words, though nothing related to colonizing practies was explicitly mentioned, the risk of such unequal forms of knowledge extraction still exists. A relationship based on the assumption that "the one who has" can help the needy "who does not have" is particularly dangerous because it reinforces prejudice and replicates power differences between those who serve and those who are served (King, 2004). Certainly, an ISL program has academic learning goals that will be fulfilled during the service; the community will also generate knowledge of different types. Ignoring these forms of knowledge in scholarship also reflects on the issues of power and privilege that remain inherent in academic research on ISL in particular and on academia in general. 


\section{Conclusion}

The qualitative findings of this research would not necessarily apply to other communities in other parts of the world. There are cultural, social, and economic factors that influence how different host communities contribute to and learn from the ISL experience. The lessons from this study, however, are important as institutions explore diverse cultural contexts for expanding ISL programs. The study illustrates that community members are undoubtedly educational agents who teach and learn in reciprocal ways (Freire, 1976; Hartman et al., 2014). In addition, cultural exchange and dialogue are effective ways to interpret the relationships between groups (Ortiz, 1940), and ISL has the potential to promote a humanized education (Cobo, 2005).

These results further suggest that the community can play more than the role of "receivers" of benefits; a new horizontal relationship can be sought and developed whereby both groups (i.e., students and community) became simultaneously students and teachers, both learning from each other, allowing the community to act as an educational agent (Freire, 1976). The implications of these findings are profound for thinking about planning ISL programs. The personal bond developed between students and the community must be strong, real, and meaningful (Plater, 2011). Higher education institutions and faculty leading such programs should be cognizant of the challenges of short-term ISL projects that are not based on long-term relationship building and in which students and the community do not engage throughout the whole process. Such a process includes planning, monitoring, and evaluating the program.

This study is important not only because it makes a non-Anglophonic ISL host community visible to the academy but also because it illustrates that education should not reproduce the existing socioeconomic order. While ISL is clearly not a strategy that can significantly transform all societies, when structured appropriately, it can help to promote and reinforce human values that generate practices that are unarguably positive to society. Yet, as a tool for promoting social equity and mutual learning that undermines stereotypes and potential conflict, such a strategy should be accompanied by social, economic, and political advocacy.

There is thus a pathway for further research about transformation, changes, and learning that result from local intercultural experiences through ISL. Future research can explore to what end ISL host communities become change agents and challenge broader systemic inequalities. Such critical scholarship would offer possibilities for further understanding the long-term role of ISL in promoting learning and positive social change for host communities. It would also offer the potential to counter inherent tendencies of ISL toward reemphasizing a more colonial model of knowledge extraction.

\section{References}

Allen, N., Boots, R., Bugas, M., Parsons, A., \& Swap, R. (2014). Arriving as strangers, welcomed as friends: Student reflections on mindsets, equity, and partnerships in international servicelearning. Journal of Community Engagement and Scholarship, 7(1), 90-95.

Baker-Boosamra, M. (2006). From service to solidarity: Evaluation and recommendations for international service learning. SPNA Review, 2(1), 1-21.

Braskamp, L. A., Braskamp, D. C., \& Merrill, K. C. (2009). Assessing progress in global learning and development of students with education abroad experiences. Frontiers: The Interdisciplinary Journal of Study Abroad, 13, 101-118.

Bringle, R. G., Hatcher, J. A., \& Jones, S. G. (Eds.). (2011). International service learning: Conceptual frameworks and research. Sterling, VA: Stylus.

Caballero, A. (2013). Los Mayas del Sur de Mérida ¿Desatino de las políticas públicas de combate a la pobreza y la marginación? Entre Irse, 379, 239-270.

Cobo, J. M. (2005). Otro mundo es posible: Propuesta de una utopía para el siglo XXI. Madrid: Bibliteca Nueva. 
Cornejo, J. (2012). Retos Impuestos por la globalización a los sistemas educativos latinoamericanos. Revista Mexicana de Investigación Educativa, 17(52), 15-37.

Cortés, F. (2007). Justicia y Exclusión . Bogotá, Colombia: Siglo del Hombre Editores.

Cox, T., Murray, L., \& Plante, J. (2014). Undergraduate student diversity paradigm expansion: The role of international service learning. International Forum of Teaching and Studies, 10(1), $3-13$.

Crabtree, R. (2013). The intended and unintended consequences of international servicelearning. Journal of Higher Education Outreach and Engagement, 17(2), 43-65.

Denzin, N., \& Lincoln, Y. (2011). La investigación cualitativa como disciplina y como práctica. En N. Denzin \& Y. Lincoln (Eds.), Manual de investigación cualitativa: El campo de la investigación cualitativa (pp. 43-102). Barcelona: Gedisa Editorial.

Freire, P. (1976). Pedagogía del oprimido. México: Siglo XXI Editores, S.A. de C.V.

Gaultier, S. (2003). Migración rural y nuevos sistemas localizados de producción: Las evoluciones territoriales de la región peninsular. En J. P. Coronado (Ed.), Territorios, actores y poder. Regionalismos emergentes en México (pp. 49-78). Mérida, México: UADY.

Geertz, C. (2005). La interpretación de las Culturas. Barcelona: Edit. Gedisa.

Hammersley, L. (2012). Community-based service-learning: Partnerships of reciprocal exchange? Asia-Pacific Journal of Cooperative Education, 14(3), 171-184.

Hartman, E., Paris, C. M., \& Blache-Cohen, B. (2014). Fair trade learning: Ethical standards for community-engaged international volunteer tourism. Tourism and Hospitality Research, 14(1-2), 108-116.

Hartman, S. (2011). NAFTA: The controversy. The International Trade Journal, 25(1), 5-34.

Hautzinger, S. (2008). From direct to referred reciprocity: Service versus community-based learning in international anthropology learning. The Applied Anthropologist: An Interdisciplinary Social Science Journal, 28(2), 192-203.

Kahn, H. E. (2011). Overcoming the challenges of international service learning: A visual approach to sharing authority, community development, and global learning. In R. G. Bringle, J. A. Hatcher, \& S. G. Jones (Eds.), International service learning: Conceptual frameworks and research (pp. 113-124). Sterling, VA: Stylus.

King, J. (2004). Service-learning as a site for critical pedagogy: A case of collaboration, caring, and defamiliarization across borders. Journal of Experiential Education, 26(3), 121-137.

Larson, J., \& Fay, M. (2016). Uncertainty management and sensemaking as precursors to transformative learning in an international immersion service-learning experience. International Journal for the Scholarship of Teaching and Learning, 10(1), Art. 6. Retrieved from https://digitalcommons.georgiasouthern.edu/ij-sotl/vol10/iss1/6/

Lizama, J., \& Bracamonte, P. (2014). Decir que somos quien somos. Compendio de resultados de encuestas a población maya de la Península de Yucatán (2004-2012). México: Raíz de Sol.

Lovett, M., \& Nain, Y. (2015). Place attachment among college students related to community engagement through service-learning. International Journal of Education Research, 10(2), $31-42$.

Martínez-Odria, A. (2008). Service-learning o aprendizaje-servicio: La apertura de la escuela a la comunidad local como propuesta de educación para la ciudadanía. Universidad de Navarra Bordón, 59(4), 627-640.

Milhouse, V., Asante, M., \& Nwosu, P. (2001). Transcultural realities: Interdisciplinary perspectives on cross-cultural relations. Thousand Oaks, CA: Sage.

Miron, D., \& Moely, B. (2006). Community agency voice and benefit in service-learning. Michigan Journal of Community Service Learning, 12(2), 27-37.

Mitchell, T. D. (2008). Traditional vs. critical service-learning: Engaging the literature to differentiate two models. Michigan Journal of Community Service Learning, 14(2), 50-65. 
14 | International Journal of Research on Service-Learning and Community Engagement

Ortiz, F. (1940). Contrapunteo Cubano del Tabaco y el Azucar. Habana: Biblioteca Historia, Filosofía y Sociología.

Plater, W. M. (2011). The context for international service learning: An invisible revolution is underway. In R. G. Bringle, J. A. Hatcher, \& S. G. Jones (Eds.), International service learning: Conceptual frameworks and research (pp. 29-56). Sterling, VA: Stylus.

Pless, N. M., Maak, T., \& Stahl, G. K. (2011). Developing responsible global leaders through international service-learning programs: The Ulysses experience. Academy of Management Learning and Education, 10(2), 237-260.

Sharp, E. (2015). Colonialist tendencies in education abroad. International Journal of Teaching and Learning in Higher Education, 27(2), 227-234.

Stratman, J. (2013). Toward a pedagogy of hospitality: Empathy, literature, and community engagement. Journal of Education and Christian Belief, 17(1), 25-59.

Stromquist, N. (2002). Globalization, the I, and the other. Current Issues in Comparative Education, 4(2), 87-94.

Stromquist, N. P. (2008). La internacionalización: Entre la promesa de la calidad y el riesgo de la homogeneización. Revista de la Educación Superior, 37(145), 89-99.

Tonkin, H., \& Quiroga, D. (2004). A qualitative approach to the assessment of international servicelearning. Frontiers: The Interdisciplinary Journal of Study Abroad, 10, 131-149.

Whitaker, W., \& Bathum, M. E. (2014). Bridging borders with Mexico: The humus of international service-learning. Partnerships: A Journal of Service-Learning \& Civic Engagement, 5(2), $104-121$.

\section{About the Author}

Claudia Chapa-Cortés is Director at TSIKBAL International Education Agency in Mérida, México.

Correspondence concerning this article should be addressed to Claudia Chapa-Cortés at cchapa@tsikbal.com.mx. 